\title{
THE RECOMBINANT FUSION PROTEIN CFP10-ESAT6-DIFN HAS PROTECTIVE EFFECT AGAINST TUBERCULOSIS IN GUINEA PIGS
}

\author{
Natalya V. Permyakova ${ }^{1 *}$, Pavel A. Belavin ${ }^{1}$, Dariya S. Pirozhkova ${ }^{1}$, \\ Elena G. Ufimtseva ${ }^{2,3}$, Sergey M. Rozov ${ }^{1}$, Sergey R. Mursalimov ${ }^{1}$, \\ Yuriy V. SidOrCHuK ${ }^{1}$, Elena A. UVArova ${ }^{1}$, Alla A. ZAGORSKAYA ${ }^{1}$, \\ TATIANA V. MARENKOVA ${ }^{1}$, SVETLANA V. BANNIKOVA ${ }^{1}$, EVGENIY A. DEMIDOV ${ }^{1}$, \\ Konstantin V. Starostin ${ }^{1}$, Marionella A. KraVChenKo ${ }^{3}$, \\ DiANA V. VAKHRUSHEVA ${ }^{3}$, ROMAN B. BERDNIKOV ${ }^{3}$, NATALYA I. EREMEEVA ${ }^{3}$, \\ Sergey N. Skornyakov ${ }^{3}$, Sergey E. Peltek ${ }^{1}$ and Elena V. Deineko ${ }^{1}$ \\ ${ }^{1}$ The Federal Research Center, Institute of Cytology and Genetics, Siberian Branch, \\ Russian Academy of Sciences, Novosibirsk, Russia \\ ${ }^{2}$ Department of Medical Biotechnology, The Research Institute of Biochemistry, \\ Novosibirsk, Russia \\ ${ }^{3}$ Ural Research Institute for Phthisiopulmonology, Ministry of Public Health of the \\ Russian Federation, Yekaterinburg, Russia
}

(Received: 2 October 2017; accepted: 13 November 2017)

Development of effective vaccine candidates against tuberculosis (TB) is currently the most important challenge in the prevention of this disease since the BCG vaccine fails to guarantee a lifelong protection, while any other approved vaccine with better efficiency is still absent. The protective effect of the recombinant fusion protein CFP10-ESAT6-dIFN produced in a prokaryotic expression system (Escherichia coli) has been assessed in a guinea pig model of acute TB. The tested antigen comprises the Mycobacterium tuberculosis (Mtb) proteins ESAT6 and CFP10 as well as modified human $\gamma$-interferon (dIFN) for boosting the immune response. Double intradermal immunization of guinea pigs with the tested fusion protein $(2 \times 0.5 \mu \mathrm{g})$ induces a protective effect against subsequent $M t b$ infection. The immunized guinea pigs do not develop the symptoms of acute TB and their body weight gain was five times more as compared with the non-immunized infected guinea pigs. The animal group immunized with this dose of antigen displays the minimum morphological changes in the internal organs and insignificant inflammatory lesions in the liver tissue, which complies with a decrease in the bacterial load in the spleen and average $M t b$ counts in macrophages.

*Corresponding author; E-mail: puh@bionet.nsc.ru 
Keywords: tuberculosis, Mycobacterium tuberculosis, recombinant fusion protein CFP10-ESAT6-dIFN, guinea pigs

\section{Introduction}

The tuberculosis (TB) caused by Mycobacterium tuberculosis (Mtb) is currently an extremely widespread disease in the world, with high morbidity and mortality rates, despite the significant advance in both medicine and vaccinology. $M t b$ is an airborne pathogen; although only $5 \%-15 \%$ of the infected individuals develop an active TB, the world cohort of $M t b$ carriers according to the WHO data currently comprises two-three billion people [1].

The only TB vaccine currently available is bacillus Calmette-Guerin (BCG), an attenuated Mycobacterium bovis strain, given soon after birth to protect against severe forms of TB in childhood. However, BCG's efficacy against pulmonary TB in adults is highly variable and depends on, among other factors, ethnicity, and geographical location [2]. Since $M t b$ resides inside the cells, the humoral immunity is insufficient for the protection of the organism from infection and development of active TB; thus, an efficient T cell-mediated immune response is necessary [3].

The intracellular Mtb localization and its ability to persist in the host body for decades have made the design of new efficient vaccines to replace BCG an unexpectedly hard task. Although manifold new anti-TB vaccines are actively designed all over the world, any vaccine exceeding BCG in its efficiency and approved for clinical use is still absent. Currently, several new generation vaccines designed using viral vectors as well as a number of subunit protein vaccines are at different stages of clinical trials [4]. The $M t b$-secreted proteins are regarded as the promising component for preventive vaccines [5]. The proteins ESAT6 (6-kDa early secretory antigenic target) and CFP10 (10-kDa culture filtrate protein) secreted at the early stage of the disease (early phase protein) are of special interest. The protein ESAT6 and its chaperon CFP10 are highly immunogenic and carry the epitopes recognized by $\mathrm{T}$ and $\mathrm{B}$ cells of $\mathrm{TB}$ patients $[6,7]$. These proteins are $M t b$ virulence factors; the corresponding genes are present only in the pathogenic mycobacteria and are absent in BCG [8].

We have demonstrated earlier that the immunization of laboratory mice with the recombinant proteins ESAT6 and CFP10 by either injection or oral administration inhibits spleen lymphocyte function [9]. Moreover, both the recombinant proteins ESAT6 and CFP10 separately and as a fusion protein are able to inhibit macrophage functions reducing production of reactive oxygen species [10]. Since the proteins ESAT6 and CFP10 display considerable immunogenicity and their epitopes are recognized by $\mathrm{T}$ and $\mathrm{B}$ cells, they are promising as immunogens when 
constructing recombinant vaccines but in a modified form. The undesirable side effects of the proteins ESAT6 and CFP10 can be reduced by the introduction of additional components into the hybrid antigens containing these proteins. In particular, administration of the recombinant fusion protein CFP10-ESAT6-dIFN with the mouse IgG2a Fc fragment to laboratory mice increased the intensity of Th-1 T-cell response accompanied by an increased IFN- $\gamma$, IL-12, and IL-4 production [11]. A statistically significant increase in the immune response to administration of the recombinant fusion protein CFP10-ESAT6-dIFN supplemented with modified human IFN- $\gamma$ (dIFN, deltaferon) as compared with these immunogens used alone has been demonstrated. Our experiments in mouse model demonstrate that this protein has no cytotoxic effect on the blood mononuclear cells and induces both the humoral and cell-mediated immune responses [12]. Thus, the considerable interest was to study the protective properties of the recombinant fusion protein CFP10-ESAT6-dIFN in a guinea pig TB model.

The guinea pig TB model is widely used to assess the efficiency of new antiTB vaccine candidates [13]. Unlike the model that utilizes mice, which are apt to develop a latent TB variant, the specific feature of the guinea pig model is that the disease course is usually acute and has a lethal outcome. This paper summarizes the results on the protective properties of the recombinant fusion protein CFP10 ESAT6-dIFN produced in a prokaryotic expression system (Escherichia coli) assessed in the guinea pig model of acute systemic TB.

\section{Materials and Methods}

\section{Ethical statement}

The guinea pig experiments were approved by the ethical committee with the Ural Research Institute for Phthisiopulmonology, Ministry of Public Health of the Russian Federation (record no. 36 of June 29, 2015).

\section{Cloning and purification of fusion protein}

The target gene encoding the recombinant fusion protein CFP10-ESAT6dIFN was cloned from the plasmid pBI121-CFP10-ESAT6-dIFN [12] into the expression vector pHis, carrying the sequence coding for a hexahistidine tract. The BamHI and HindIII restriction endonuclease sites were introduced into the target gene by PCR using the primers $5^{\prime}$-CCCGGATCCATGGCAGAGATGAAGACCGAT-3' and 5'-CCCAAGCTTTTACTGGGATGCTCTTCGACC-3', respectively (restriction sites are italicized). E. coli strain BL21(DE3) transformed with 
the constructed plasmid pHis-chimera was used to obtain the recombinant fusion protein CFP10-ESAT6-dIFN. The synthesis of the recombinant fusion protein CFP10-ESAT6-dIFN was induced with $1 \mathrm{mM}$ isopropyl $\beta$-D-1thiogalactopyranoside.

To isolate the recombinant fusion protein CFP10-ESAT6-dIFN, bacterial cells were sonicated (Sonics Vibra Cell, USA). The sediment after centrifugation of the bacterial lysate was dissolved in the buffer containing $100 \mathrm{mM} \mathrm{NaH}_{2} \mathrm{PO}_{4}, 10 \mathrm{mM}$ Tris- $\mathrm{HCl}$, and $8 \mathrm{M}$ urea (pH 8.0) and loaded onto the Ni-NTA agarose (Qiagen cat. \#30210) according to the manufacturer's recommendations. The recombinant fusion protein CFP10-ESAT6-dIFN was further purified by dialysis against phosphate buffered saline (PBS) pH 7.4. Protein concentration was determined according to Bradford [14]. The particle size in the recombinant fusion protein CFP10-ESAT6dIFN suspension was assessed in a transmitted light using an AxioScope2plus (Zeiss) microscope equipped with an AxioCam HRc (Zeiss) camera.

The presence of the recombinant fusion protein CFP10-ESAT6-dIFN in bacterial biomass was confirmed by Western blot using Millipore nitrocellulose membrane $(0.45 \mu \mathrm{m})$, polyclonal serum of the rabbit immunized with ESAT6 protein, and peroxidase-conjugated goat anti-rabbit IgG (Jackson ImmunoResearch, cat. \#11-035-144) as primary and secondary antibodies. Pierce ${ }^{\circledR}$ ECL Western Blotting Substrate (Thermo Scientific, cat. \#32209, USA) and Kodak X-ray film were used for visualization. As a negative control, we used bovine serum albumin (BSA).

The primary structure of the recombinant fusion protein CFP10-ESAT6-dIFN was verified by mass spectrometry assay. After denaturing electrophoresis, the corresponding protein fractions were cut off of the polyacrylamide gel with an EXQuest spot cutter (BioRad, USA) and lysed with trypsin. The tryptic peptides were purified and assayed using an Ultraflex III (Bruker, Germany) mass spectrometer.

\section{Guinea pigs}

Female guinea pigs were obtained from the Science and Production Association for Medical and Immunological Preparations Mikrogen (Bashkortostan, Russia) and kept under standard conditions with ad libitum access to food and water.

\section{Immunization and infection of guinea pigs}

The guinea pigs were immunized at an age of 2 months (weight: $300-320 \mathrm{~g}$ ). The recombinant fusion protein CFP10-ESAT6-dIFN suspension ( $0.5 \mathrm{ml}$ in PBS $\mathrm{pH}$ 7.4) was intradermally injected in the nuchal fold. Either single (1.0 or $4.0 \mu \mathrm{g}$ protein) or double $(0.25,0.5,1.0,2.0$, or $4.0 \mu \mathrm{g}$ protein with 14 -day interval) 
immunization was used. In total, seven experimental groups immunized with different doses of the recombinant fusion protein CFP10-ESAT6-dIFN, a comparative and a negative control groups (three guinea pigs in each group) were assayed. The guinea pigs of the comparative group (Tub) received $2 \mathrm{TU}$ of tuberculin/purified protein derivate (PPD) (St. Petersburg Institute of Vaccines and Sera and Plant for Production of Bacterial Preparations, Russia) twice with a 14-day interval. The guinea pigs of negative control group $(\mathrm{C}-)$ received PBS.

On day 28 after the first immunization, the guinea pigs were subcutaneously (right inguinal skin fold) infected with $0.2 \mathrm{ml}$ of the suspension of the same 21-day virulent $M t b \mathrm{H} 37 \mathrm{Rv}$ culture containing $0.002 \mathrm{mg}$ of the pathogen $\left(2 \times 10^{5}-2 \times 10^{6}\right.$ CFU), according to the order of the Minister of Health of USSR No. 558 of June, 7,1987 . The infection intensity was assessed according to the change in guinea pig's body weight, state of the internal organs in autopsied guinea pigs (including histological examination of the lungs, liver, and spleen), growth rate of the Mtb from spleen homogenates on Lowenstein-Jensen (LJ) medium, and the number of $M t b$-infected macrophages isolated from the spleen of infected guinea pigs. The guinea pigs were weighed five times starting from day 1 of infection (first weighing, day 28 after the first immunization) to euthanasia (fifth weighing, day 114 after infection and day 142 after the first immunization).

\section{Sample preparation}

The guinea pigs were euthanized with Lysthenon (Nycomed Austria GmbH, Austria) on day 142 after the first immunization (day 114 after infection). The macropathological changes in internal organs of guinea pigs were examined during autopsy.

For histological examination of the lungs, liver, and spleen tissues, the specimens were fixed with $10 \%$ neutral formalin solution. The specimens were processed in an STP 120-3 (Thermo Scientific, Germany) tissue processor using isopropanol and mineral oil. The sections $(4-\mu \mathrm{m}$ thick) were stained with hematoxylin and eosin.

Macrophages were isolated from the spleen of infected guinea pigs under sterile conditions. For this purpose, spleen samples were minced with scissors in the RPMI 1640 medium (Biolot, Russia) supplemented with $2 \mathrm{mM}$ glutamine (Biolot) and $50 \mu \mathrm{g} / \mathrm{ml}$ gentamicin (Biolot). The cells were placed into 24 well plates (Orange Scientific, Belgium) with cover glasses on the well bottom $\left[3 \times 10^{5}\right.$ cells/well in $0.5 \mathrm{ml}$ of the RPMI 1640 medium with $10 \%$ fetal bovine serum (Biolot), $2 \mathrm{mM}$ glutamine, and $50 \mu \mathrm{g} / \mathrm{ml}$ gentamicin] [15]. The cells were fixed with $4 \%$ formalin after 16 -h cultivation $\left(+37^{\circ} \mathrm{C}, 5 \% \mathrm{CO}_{2}\right)$ and stained according 
to Ziehl-Neelsen method with the corresponding straining kit (Pervaya Laboratornaya Companiya, Russia) according to the manufacturer's protocol.

Microscopy

Cytological and histological slides were examined at the Shared Access Center for Microscopy of Biological Objects with the Institute of Cytology and Genetics (Siberian Branch, Russian Academy of Sciences, Novosibirsk, Russia) using an AxioScope2plus (Zeiss) microscope equipped with an AxioCam HRc (Zeiss) digital camera with the help of AxioVision 4.7 (Zeiss) software.

\section{Bacterial enumeration}

The bacterial load in the guinea pig spleens was assessed according to the $M t b$ growth rate on dense LJ medium in two replicates. For preparation of culture inoculum, spleen specimens were placed into $10 \%$ sodium phosphate $\left(\mathrm{Na}_{3} \mathrm{PO}_{4}\right)$, stirred for $10 \mathrm{~min}$, and incubated for $18-20 \mathrm{~h}$ at $+37{ }^{\circ} \mathrm{C}$. The spleen specimens were then minced, homogenized, and centrifuged for $15 \mathrm{~min}$ at $3,000 \times g$; the sediment was neutralized with $1 \%$ citric acid solution. After washing with $15 \mathrm{ml}$ of distilled water, the sediment was again centrifuged $(15 \mathrm{~min}, 3,000 \times g)$ and suspended in $1 \mathrm{ml}$ of distilled water to plate $0.5 \mathrm{ml}$ of the suspension onto dense nutrient medium. The tubes were incubated at $+37^{\circ} \mathrm{C}$ for 10 weeks with obligatory visual control on a weekly basis. The growth intensity was assessed according to the number of colonies (CFU) grown from each sample.

\section{Statistics}

All data are given as the mean \pm SD and \pm SEM. Non-parametric KruskalWallis test with subsequent pairwise multiple comparison by Dunn's test (Statistica 5.5 software package) was used for analyzing the between-group differences in body weight. The significance level cut-off value $(\alpha)$ was $5 \%$. The differences in the relative counts of the infected macrophages in different groups were analyzed by one-way analysis of variance.

\section{Results}

The recombinant fusion protein CFP10-ESAT6-dIFN used for immunization

Figure 1A shows the scheme of the gene encoding the recombinant fusion protein CFP10-ESAT6-dIFN. This gene comprises four domains, namely, his6, coding for polyhistidine tract; cfp10 and esat6, the genes coding for the 


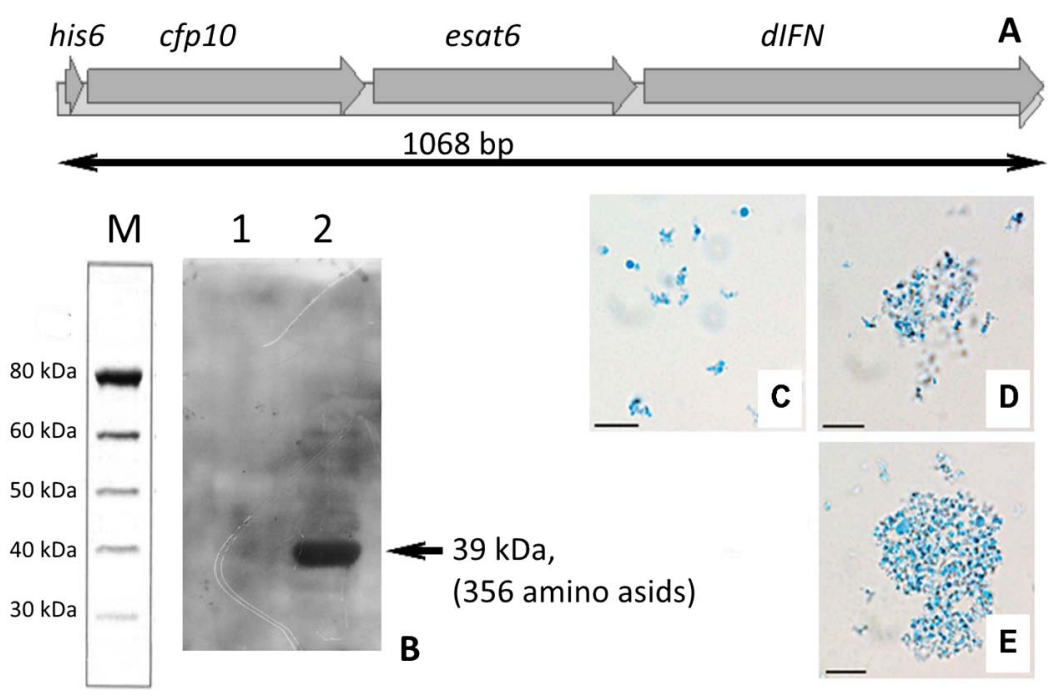

Figure 1. Chimeric gene $c f p 10-e s a t 6-d I F N$ and the encoded protein. (A) Structure of the gene encoding the recombinant fusion protein CFP10-ESAT6-dIFN; (B) Western blot pattern; and C-E: the recombinant fusion protein CFP10-ESAT6-dIFN aggregates in the suspension for injection, including (C) small, (D) medium-sized, and (E) large. his6, polyhistidine tract; cfp10 and esat6, the genes coding for the corresponding $M t b$ proteins CFP10 and ESAT6; $d I F N$, the gene coding for modified human IFN- $\gamma$ (deltaferon); M, molecular weight markers; 1 , negative control (BSA); 2 , the recombinant fusion protein CFP10-ESAT6-dIFN (arrow denotes the major fraction)

corresponding $M t b$-secreted proteins, CFP10 and ESAT6; and $d I F N$, the gene coding for modified human IFN- $\gamma$ (deltaferon). The nucleotide sequences encoding the above-listed genes were supplemented with ggcgcgggg sequences, encoding a Gly-Ala-Gly hinge to spatially separate the protein domains. The recombinant fusion protein CFP10-ESAT6-dIFN comprised 356 amino acids and its expected molecular weight was $39 \mathrm{kDa}$.

The recombinant fusion protein CFP10-ESAT6-dIFN produced in E. coli was produced in an insoluble form with a yield of $3 \mathrm{mg} / \mathrm{L}$ bacterial culture. The recombinant fusion protein CFP10-ESAT6-dIFN was purified and its presence was confirmed by Western blot assay (Figure 1B). The major band (arrow) corresponded to the expected molecular weight of the recombinant fusion protein CFP10-ESAT6-dIFN (39 kDa). The minor fractions with a larger molecular weight (Figure 1B), which also bound polyclonal antibodies to ESAT6 protein, are most likely the aggregates of the recombinant fusion protein CFP10-ESAT6dIFN and/or its parts.

The primary structure of the recombinant fusion protein CFP10-ESAT6dIFN was confirmed by mass spectrometry assay. The suspension in PBS where 
the recombinant fusion protein CFP10-ESAT6-dIFN was present as particles with a size of $0.5-3.0 \mu \mathrm{m}$ was used to immunize guinea pigs.

\section{Protective effect of the recombinant fusion protein CFP10-ESAT6-dIFN}

A protective effect of the recombinant fusion protein CFP10-ESAT6-dIFN was assessed according to the change in the guinea pig's body weight after $M t b$ infection and the bacterial load. A large body size of guinea pigs allows for estimation of the body weight loss, which is an adequate indicator for TB infection development [16]. The change in body weight was assessed as the difference between a next weighing and the initial value (on the day of infection with $M t b$ ) and the subsequent calculation of the mean weight change for each group. The interval between weighing was 28 days. The experiment was completed on day 114 after infection, when the first guinea pig died in the negative control group. Figure 2A shows the dynamics of the changes in the body weight of guinea pigs. The dynamics of weight change of an intact guinea pig not infected with Mtb (dashed line, intact control) is plotted for comparison. Figure 2B shows the changes in guinea pig's body weight by the end of experiment (day 114 after infection).

As compared with the intact control, the group of guinea pigs immunized twice with $0.5 \mu \mathrm{g}$ of the recombinant fusion protein CFP10-ESAT6-dIFN with an interval of 14 days (Figure 2A, solid line with square dots) displayed a stable
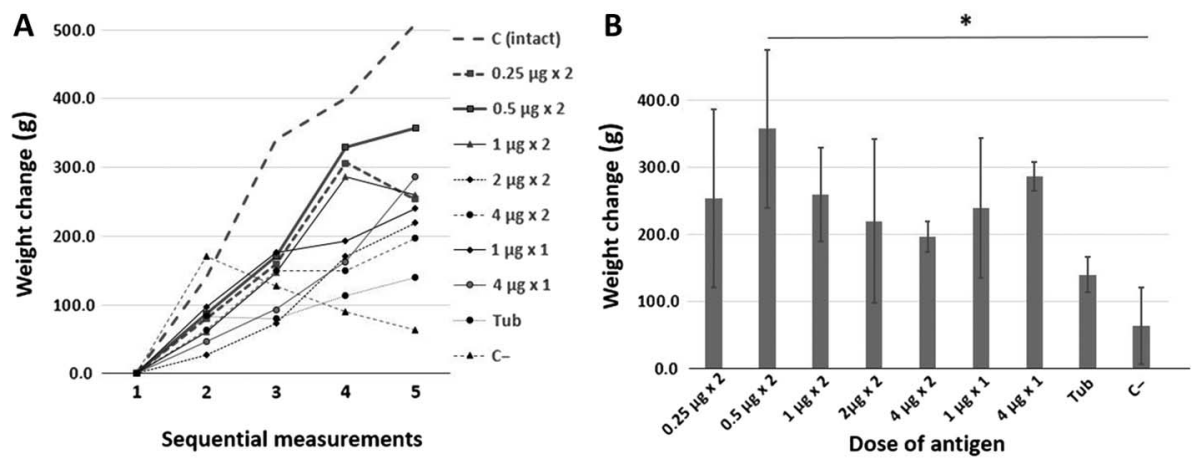

Figure 2. Dynamics of guinea pig's body weight after $M t b$ infection and the mean change in body weight by the end of experiment. (A) The dynamics of changes in body weight over the infection period (114 days) and (B) the mean change in body weight ( \pm SD) on day 114 after infection. Designations: $1-5$, sequential number of measurements made with an interval of 28 days; C (intact), intact control group (without immunization and $M t b$ infection); Tub, comparative group (immunization with tuberculin); and $\mathrm{C}-$, negative control group (without immunization), ${ }^{*} p<0.05$ 
increase in body weight during the entire experiment. Only a small weight loss between measurements 4 and 5 was observed in this group. The guinea pigs immunized with half dose (two immunizations of $0.25 \mu \mathrm{g}$ each; Figure $2 \mathrm{~A}$, dashed line with square dots) and double dose (two immunizations of $1.0 \mu \mathrm{g}$ each; Figure 2A, solid line with triangle dots) of the recombinant fusion protein CFP10ESAT6-dIFN also displayed a weight loss between the two last measurements. Kruskal-Wallis analysis of the data on the increase in guinea pig's body weight in nine studied groups demonstrated a statistically significant differences between the groups $(H=16.5004, p=0.0358)$. The statistically significant differences $\left(Q=3.268, Q_{\text {critical }}=3.197, k=9, \alpha=0.05\right)$ for the weight change in the examined animal groups relative to the negative control, group $\mathrm{C}-$ (without immunization), were detectable on day 114 after the infection only for the guinea pigs immunized twice with the recombinant fusion protein CFP10-ESAT6-dIFN at a dose of $0.5 \mu \mathrm{g}$ (Figure 2B).

Figure 3 shows the content of $M t b$ in the spleen specimens of the infected guinea pigs immunized with different doses of the recombinant fusion protein CFP10-ESAT6-dIFN on LJ medium.

Note that a decrease in the bacterial load in the spleen of infected guinea pigs relative to the unimmunized control (group $\mathrm{C}-$ ) was observed in the groups immunized with either the recombinant fusion protein CFP10-ESAT6-dIFN or

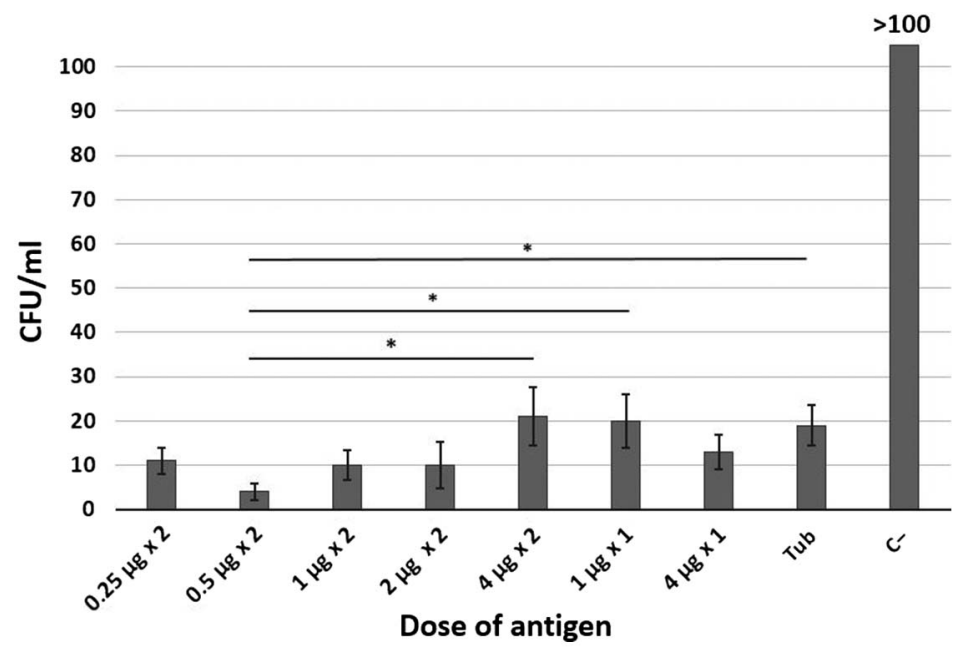

Figure 3. The content of $M t b$ in the spleen specimens of the infected guinea pigs immunized with different doses of the recombinant fusion protein ESAT6-CFP10-dIFN. Designations: Tub, comparative group (immunization with tuberculin) and $\mathrm{C}-$, negative control (without immunization), $* p<0.05$ 
tuberculin. In a group immunized twice with $0.5 \mu \mathrm{g}$, the bacterial load in the spleen was significantly lower than in the comparison group (group Tub) and in groups immunized twice with $4 \mu \mathrm{g}$ and once with a dose of $1 \mu \mathrm{g}$.

\section{Morphological manifestation of TB lesions in guinea pigs}

All guinea pigs infected with $M t b$ displayed the signs of TB infection in their internal organs. Comparative examination of the visceral organs of the infected guinea pigs demonstrated that in the group of guinea pigs immunized twice with $0.5 \mu \mathrm{g}$ of the recombinant fusion protein CFP10-ESAT6-dIFN, the overall morphological pattern was more consistent with that of the intact guinea pigs than in the negative control ( $\mathrm{C}-$ group, without immunization) and in the group receiving tuberculin (Tub group) (Figure 4M-O).

Histological examination of the spleen of the group immunized twice with $0.5 \mu \mathrm{g}$ of the recombinant fusion protein CFP10-ESAT6-dIFN demonstrated a clear separation of the spleen tissue into white and red pulp. Follicles had a clear structure, with pronounced germinal centers (Figure 4A). Single follicles tended to merge. Follicles in Tub group were small and without pronounced germinal centers (Figure 4B), while in the group C- follicles often did not have the clear structure (Figure 4C). The ratio between white and red pulp was disrupted with a predominance of white pulp (Figure 4B and C). In both forenamed groups, fibrosing zones and necrosis loci also were visualized, both in white and red pulp with foci of hemorrhages.

According to the results of the histological examination, the lungs in the group of guinea pigs immunized twice with $0.5 \mu \mathrm{g}$ of the recombinant fusion protein CFP10-ESAT6-dIFN had a normal structure on the whole (Figure 4D). Nevertheless, there were visualized rare foci of mononuclear cell infiltration and single granulomas consisting of macrophages, lymphocytes, fibroblasts, and single neutrophils with a predominant perivascular location (Figure 4G). Simulataneously in the negative control group (C- group) as well as in the Tub group, the presence of multiple granulomas characterized by a large number of neutrophils and macrophages in their composition (Figure 4E and F) and pneumonia with large-scale necrosis and hemorrhage zones was documented with complete disruption of the lung structure (Figure $4 \mathrm{H}$ and I).

Histological examination of the liver has demonstrated only a few inflammation TB lesions represented by small areas with diffuse infiltration of mononuclear cells in the group of guinea pigs immunized twice with $0.5 \mu \mathrm{g}$ of the recombinant fusion protein CFP10-ESAT6-dIFN (Figure 4J). In the liver of this group, only small single granulomas were visualized. The presence of infiltration 


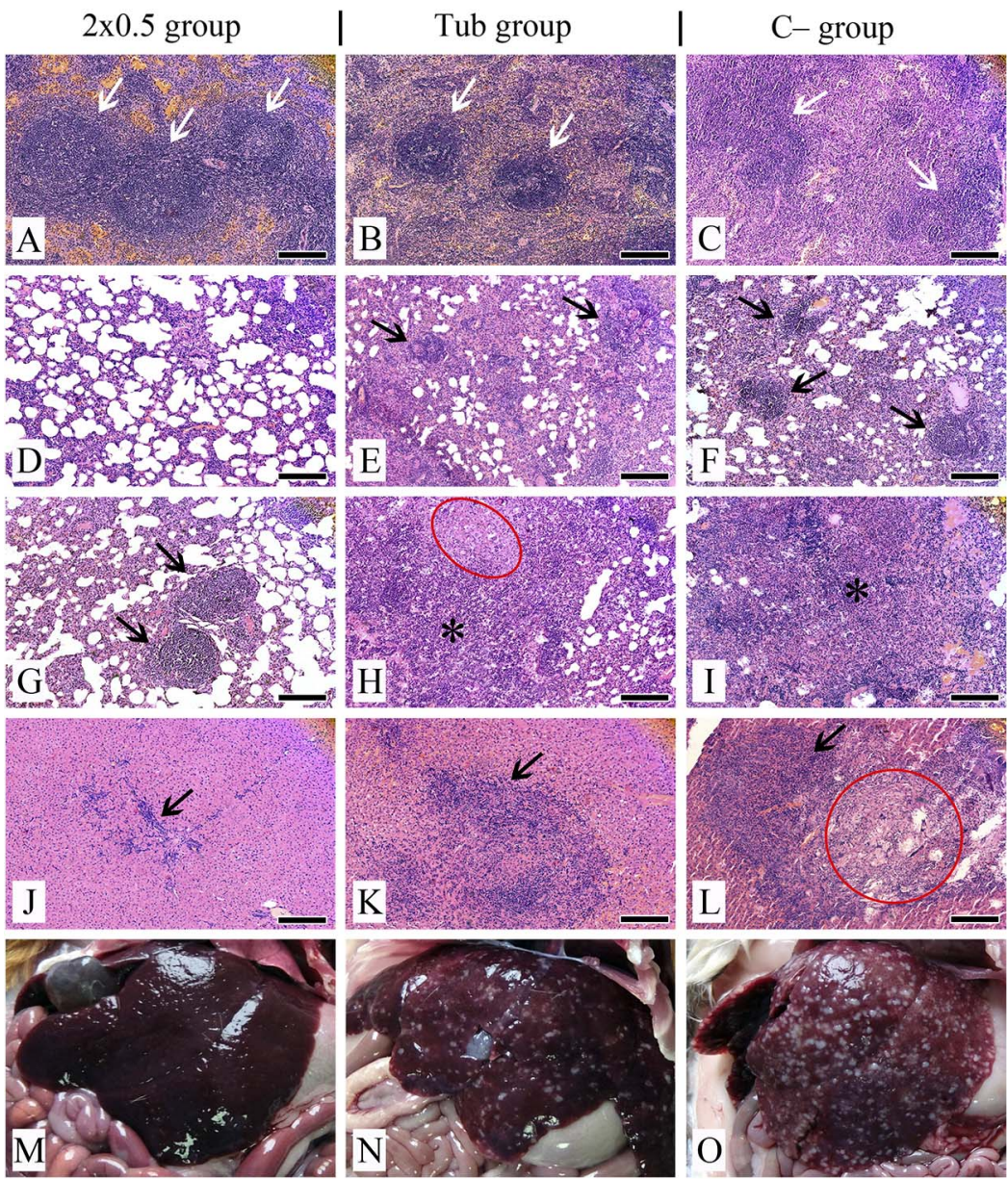

Figure 4. Histopathological $(\mathrm{A}-\mathrm{L})$ and comparative $(\mathrm{M}-\mathrm{O})$ examination of the visceral organs in experimental and control groups on day 114 after infection with $M t b$. (A-C) - spleen (follicles designated by arrows); (D-I) - lungs; (J-O) - liver. (A) - follicles with a normal structure and pronounced germinal centres; (B) - small follicles with not pronounced germinal centres, predominance of white pulp; $(\mathrm{C})$ - follicles with not pronounced structure, predominance of white pulp; (D) - lung section with normal tissue structure; (E-G) - granulomas (arrows); (H, I) pneumonia (asterisks) and necrosis zone (red oval); $(\mathrm{J})$ - mononuclear cell infiltration and weak proliferation of bile ducts (arrow); (K) - granuloma with epithelioid cells (arrow); (L) - granuloma (arrow) with necrosis zone (red circle); (M) - liver in the norm; $(\mathrm{N}, \mathrm{O})$ - liver with foci of caseous necrosis. Tissue sections were stained by hematoxylin/eosin. Scale bars are $50 \mu \mathrm{m}$

was recorded also in the triad area. Vessels were full-blooded without the tendency to thrombosis. As for the remaining examined animal groups (Tub and $\mathrm{C}-$ groups), the liver tissues were to a considerable degree replaced by 
aggregations of granulomas. Granulomas were larger, with a tendency to association and fibrosing (Figure 4K). There were detected large-scale hemorrhage zones, necrosis zones, and full-blooded sinusoids (Figure 4L). Vessels were full-blooded with a tendency to thrombosis.

$M t b$ in guinea pig spleen macrophages

The isolated spleen macrophages after $16 \mathrm{~h}$ of cultivation in ex vivo culture were stained according to Ziehl-Neelsen method to visualize acid-fast $M t b$ with an undamaged cell wall. The average interval between the divisions of $M t b \mathrm{H} 37 \mathrm{Rv}$ is approximately 20-24 h and macrophages were cultivated for $16 \mathrm{~h}$; thus, it is possible to regard that the $M t b$ counts in cells and the relative number of infected cells did not change during ex vivo cultivation [15]. The Mtb in guinea pig macrophages has a coccoid shape and a size of $0.5-1.5 \mu \mathrm{m}$. Spleen macrophages contained both solitary mycobacterial cells (Figure 5B-E) and aggregates of $M t b$, formed as a result of division (Figure $5 \mathrm{E}$ and $\mathrm{F}$ ).

Figure 6 shows the number of spleen macrophages infected by $M t b$ in different groups of experimental and control guinea pigs. The number of $M t b$-infected
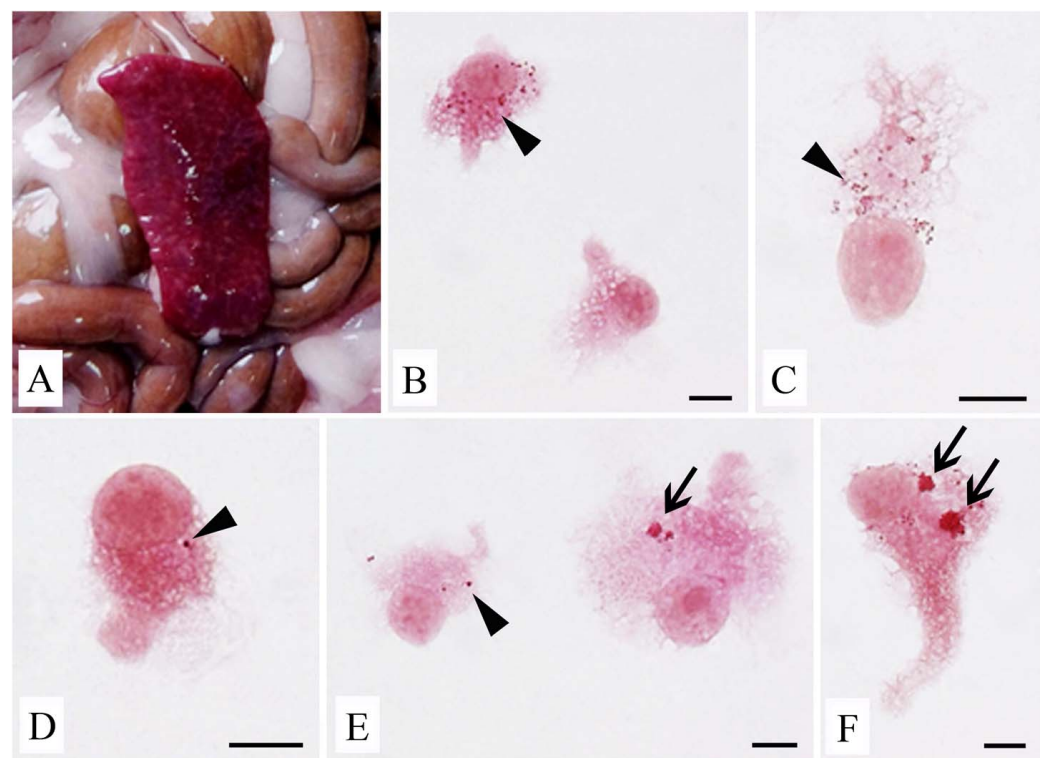

D

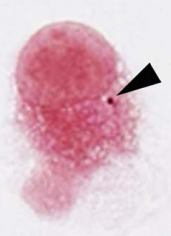

B

Figure 5. Macrophages from the spleen of $M t b$-infected guinea pigs (staining by Ziehl-Neelsen method). (A): Spleen, general view; (B-E): Macrophages containing solitary acid-fast Mtb (black arrowheads); (E and F): Macrophages with $M t b$ aggregates (black arrows). Scale bars are $10 \mu \mathrm{m}$ each 


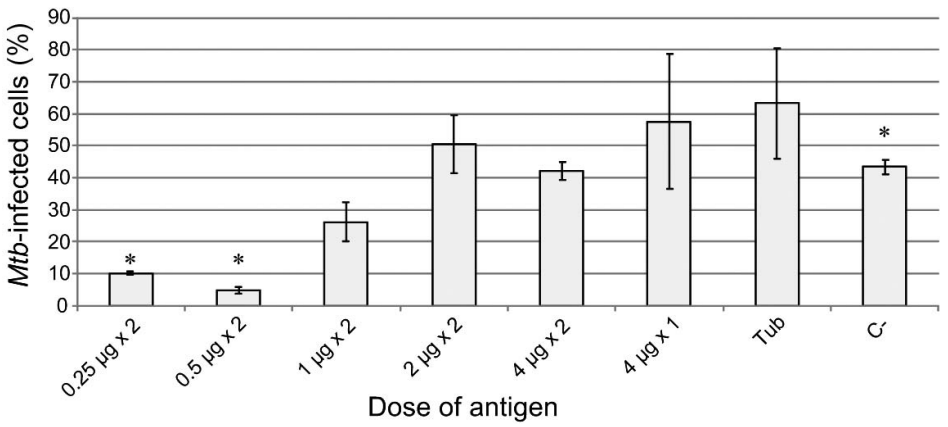

Figure 6. The number of $M t b$-infected macrophages isolated from the spleen of guinea pigs from different experimental, comparative group Tub (immunization with tuberculin) and $\mathrm{C}-$, negative control group (without immunization), expressed as a percentage of the total number of spleen macrophages. Data are expressed as the means \pm SEM. $* p<.05$ [comparisons of data in experimental groups $2 \times 0.25$ or $2 \times 0.5 \mu \mathrm{g}$ and negative control group $\mathrm{C}$ - (without immunization)]

macrophages was less than $10 \%$ and 5\% only in two experimental groups, namely the groups where guinea pigs were twice immunized with the recombinant fusion protein CFP10-ESAT6-dIFN at a dose of $2 \times 0.25$ and $2 \times 0.5 \mu \mathrm{g}$, respectively.

The number of the infected spleen macrophages containing $M t b$ aggregates did not differ between studied groups in a statistically significant manner and amounted to $40 \%-70 \%$ of all infected macrophages. The average number of $M t b$ in infected macrophages is approximately the same in all groups of immunized guinea pigs, varying from four to nine per macrophage. The distributions of spleen macrophages according to the number of mycobacteria they contain are also similar in the examined animal groups except for the negative control group (group $\mathrm{C}-$, without immunization), where some macrophages carried 50 and even more mycobacteria.

Thus, the immunization with the recombinant fusion protein CFP10 ESAT6-dIFN, at a dose of $2 \times 0.25$ or $2 \times 0.5 \mu \mathrm{g}$ led to a considerable decrease in the number of $M t b$-infected macrophages in the guinea pig spleen. Nonetheless, the mycobacteria that survived in spleen macrophages retained their functional status in the host cells, since the number of cells with reproducing Mtb is comparable in all analyzed animal groups.

\section{Discussion}

The major principles in vaccine design have not changed much since the late 18th century. The empirical paradigm "isolate, inactivate, inject" even now 
remains the most successful in the creation of most vaccines [17]. However, this approach loses its effectiveness in the case of $M t b$. The novel methodological principles of next-generation vaccine design have established over the last decade and offered the new opportunities in designing efficient anti-Mtb vaccines. The new paradigm consists in a comprehensive study of the pathogen and the mechanisms of its interaction with the immune system as well as isolation of its key antigens and only then in an informed construction of hybrid genetic systems able to induce an efficient immune response when introduced into the body $[4,18,19]$. Such vaccines are safer, since they do not contain any live mycobacteria or their lysates but rather carry the most immunogenic antigenic epitopes of the pathogen.

$M t b$ is able to persist in the body of a carrier for a long time without causing TB development [1]. Mycobacteria in the course of long-term coevolution with the host have acquired specific mechanisms allowing them to enter macrophages and survive there as well as to modulate the host immune system. Secretion of specific bacterial proteins is what allows this pathogen to persist in macrophages and modulate the immunity [20]; thus, many of these proteins can be used as antigens for subunit recombinant vaccines.

Several hundreds of $M t b$ antigens promising for the construction of new subunit vaccines are known now [21]. Most tested subunit vaccines contain the proteins belonging to $M t b$ major secreted antigen complex (Ag85), in particular, the proteins Ag85A and Ag85B, as well as an early secretory protein ESAT6 [22].

Two early secretory proteins CFP10 and ESAT6 (currently both proteins are regarded as promising components for subunit recombinant vaccines) were used for constructing the recombinant fusion antigen CFP10-ESAT6-dIFN. Both CFP10 and ESAT6 proteins induce a pronounced delayed-type hypersensitivity response [23] in guinea pigs, suggesting that they are strong T-cell antigens and induce a pronounced T-cell response.

The proteins CFP10 and ESAT6 at a ratio of 1:1 interact to form a stable complex with a more pronounced secondary structure as compared with each protein alone [24]. The C-terminal region of CFP10 protein in this complex is free and plays an important role in binding to the macrophage surface. The ESAT6: CFP10 protein complex is able to enter the macrophage endoplasmic reticulum and binds to $\beta 2$-microglobulin, thereby decreasing the expression of MHC-I molecules on the surface of infected cells and inhibiting the presentation of MHCI-restricted antigens [25]. The ESAT6 protein is the major player in this effect of the ESAT6:CFP10 protein complex. Since the C-terminal region of ESAT6 molecule in this complex is inaccessible for binding to $\beta 2$-microglobulin, this protein will not interfere with the presentation of MHC-I-restricted epitopes (the accessibility of ESAT6 C-terminal region end is essential for this effect [25]). 
The recombinant fusion protein CFP10-ESAT6-dIFN produced in a bacterial expression system (E. coli) is insoluble in buffer aqueous solutions. After the isolation and purification procedures, the recombinant fusion protein CFP10ESAT6-dIFN in PBS was represented by the particles with a size of 0.5-3.0 $\mu \mathrm{m}$. According to Champion et al. [26], this is the optimal size range for macrophages to engulf the particles. Thus, it is no need in additionally using any absorptionpromoting adjuvants, such as, for example, involving aluminium compounds [27], to enhance efficient phagocytosis of the recombinant fusion protein CFP10 ESAT6-dIFN. The aluminium-containing adjuvants are widely used in medicine, but their application has certain limitations because of Th2 polarization of the immune response, undesirable in the case of TB [28].

When designing a vaccine, it is necessary to consider that a considerable part of the population is already infected with $M t b$; thus, the vaccination has to solve this problem as well. Therefore, the models of primary infection with acute manifestation, latent $\mathrm{TB}$, and reactivation of former $\mathrm{TB}$ are used for assessing the protective effect and immunogenicity of TB vaccine candidates. The guinea pig model of primary TB infection is illustrative for vaccine protective effect, because the induced disease proceeds in an acute manner with pronounced changes in the morphology of affected organs (these model guinea pigs usually do not develop a latent TB disease [16]). Note that we have utilized an original model with subcutaneous infection, which induces a generalized TB form rather than primary lung $\mathrm{TB}$, developing in the case of an inhalational infection. We have earlier demonstrated that the recombinant fusion protein containing the $M t b$ antigens ESAT6 and CFP10 together with modified human IFN- $\gamma$ (deltaferon) induces production of specific antibodies and antigen-specific proliferation of the peripheral blood mononuclear cells in the guinea pig immunized by injection or orally [12].

This work demonstrates that the tested recombinant fusion protein CFP10 ESAT6-dIFN is capable of protecting the guinea pigs in the model of acute systemic TB. It is shown that double intradermal administration of the recombinant fusion protein CFP10-ESAT6-dIFN $(2 \times 0.5 \mu \mathrm{g})$ induced the optimal protective effect. The guinea pigs immunized with this dose according to this scheme displayed no symptoms of acute TB and gained body weight better as compared with the unimmunized guinea pigs in a statistically significant manner. Autopsy demonstrates that the guinea pigs of this experimental group have developed the minimal number of morphological changes in their internal organs and insignificant inflammatory lesions in their lung, liver, and spleen tissues.

The protective effect of the recombinant fusion protein CFP10-ESAT6dIFN against $M t b$ infection was significantly lower when the guinea pigs received (once or twice) other doses of this antigen. Presumably, a decrease in the 
protective effect of the studied recombinant fusion protein CFP10-ESAT6-dIFN is associated with the ability of this protein it contains to suppress mononuclear cells [10]. The ability of CFP10 and ESAT6 proteins to inhibit the response of mouse spleen lymphocytes to non-specific stimulation with phytohaemagglutinin was described earlier [9].

Our results suggest that an important factor in guinea pig immunization is an adequate dose of the introduced antigen; in this case, the optimal dose was $0.5 \mu \mathrm{g}$ and the recombinant fusion protein CFP10-ESAT6-dIFN intradermally injected twice $(2 \times 0.5 \mu \mathrm{g})$. Another administration scheme or overdosage of the recombinant fusion protein CFP10-ESAT6-dIFN significantly decreased the protective effect; the mechanism of this decrease is vague.

Immunization of mice with the recombinant fusion protein CFP10-ESAT6dIFN was shown to increase the T-cell immune response, and the effect was even more pronounced when supplementing the fusion protein with Fc receptor [11]. The protective effect of a recombinant protein comprising two $M t b$ antigens, ESAT6 and Ag85B, was demonstrated in a guinea pig model [29]. Note that the protective effect of the fused protein ESAT6-Ag85B was higher as compared with the effects of each protein alone but still yielded to the protective effect caused in guinea pigs by BCG immunization. The experimental data [29] demonstrate that the protection against $M t b$ provided by the recombinant fusion protein comprising these two antigens (ESAT6 and Ag85B) was close to that of BCG.

In our experiment, both experimental and control guinea pigs were euthanized and autopsied on day 114 after the infection with Mtb. Further examination demonstrated that the experimental guinea pigs immunized twice with the recombinant fusion protein CFP10-ESAT6-dIFN at a dose of $0.5 \mu \mathrm{g}(2 \times 0.5 \mu \mathrm{g})$ developed only insignificant signs of TB infection. It should be emphasized that the mycobacteria load of the spleen tissues in this particular experimental group decreased at least 30-fold as compared with the negative control. Our results considerably exceed the effect of vaccination with the recombinant protein MTB41 [30]. The mycobacteria load in the mice vaccinated with the fusion protein ESAT6-Ag85B-MPT64(190-198)-Mtb8.4-Rv2626c and subsequently infected decreased maximum 18-fold [31].

When entering the body, $M t b$ interacts with the host immune system through various cell types, including macrophages, dendritic cells, alveolar epithelial cells, neutrophils, and natural killer cells. These cells are focused on not only Mtb detection and destruction, but also triggering of the adaptive or specific host immune response; yet $M t b$ during their evolution has developed rather numerous strategies to escape the host defense mechanisms. For example, a macrophage actively phagocytizes $M t b$, but the bacterium prevents the fusion of a phagosome and lysosome and maturation of phagolysosome, providing its own long-term 
existence within the macrophage. It is possible to assess the degree of stability ("preparedness") of the body to control this infection considering these specific features in the interaction between macrophage and Mtb. The Mtb counts in the spleen macrophages of different groups of experimental guinea pigs demonstrate that the number of $M t b$-infected macrophages was significantly lower in two animal groups as compared not only with the control (immunization with tuberculin and no immunization at all), but also with the other experimental groups immunized with higher doses of the recombinant fusion protein CFP10 ESAT6-dIFN; these groups are the groups immunized twice with the recombinant fusion protein CFP10-ESAT6-dIFN at a dose of 0.25 and $0.5 \mu \mathrm{g}$ protein $(2 \times 0.25$ and $2 \times 0.5 \mu \mathrm{g})$. The average number of infected spleen macrophages in the guinea pigs that received a dose of $2 \times 0.5 \mu \mathrm{g}$ the recombinant fusion protein CFP10-ESAT6-dIFN was almost 10-fold lower as compared with the negative control (without immunization) and the proportion of macrophages with actively proliferating $M t b$ decreased twofold, respectively. Our results confirm a decrease in the bacterial load in the guinea pigs of these groups.

Thus, we have demonstrated that the tested recombinant fusion protein CFP10-ESAT6-dIFN has a pronounced protective effect in the guinea pig model of acute TB with a trend to exceed the effect of tuberculin, used as comparative control. It is of interest to further study the parameters of the T-cell response induced by the recombinant fusion protein CFP10-ESAT6-dIFN and to characterize the role of modified human IFN- $\gamma$ (deltaferon) within this fusion protein.

\section{Acknowledgements}

The work was supported by the Program of Siberian Branch of Russian Academy of Science "Genetic bases of biotechnology and bioinformatics," Project 0324-2018-0017.

\section{Conflict of Interest}

The authors declare no conflict of interest regarding the publication of this article.

\section{References}

1. World Health Organization [WHO]: WHO Global tuberculosis report 2016 (2016). Available at http://www.who.int/tb/publications/global_report/en/ 
2. Mangtani, P., Abubakar, I., Ariti, C., Beynon, R., Pimpin, L., Fine, P. E., Rodrigues, L. C., Smith, P. G., Lipman, M., Whiting, P. F., Sterne, J. A.: Protection by BCG against tuberculosis: A systematic review of randomised controlled trials. Clin Infect Dis 58, 470-480 (2013). Available at https://academic.oup.com/cid/article/58/4/470/347668/ Protection-by-BCG-Vaccine-Against-Tuberculosis-A

3. Kaufmann, S. H. E.: Tuberculosis vaccines: Time to think about the next generation. Semin Immunol 25, 172-181 (2013). Available at http://www.sciencedirect.com/science/article/ pii/S1044532313000225

4. Evans, T. G., Schrager, L., Thole, J.: Status of vaccine research and development of vaccines for tuberculosis. Vaccine 34, 2911-2914 (2016). Available at http://www. sciencedirect.com/science/article/pii/S0264410X16002929

5. Andersen, P.: Effective vaccination of mice against Mycobacterium tuberculosis infection with a soluble mixture of secreted mycobacterial proteins. Infect Immun 62, 2536-2544 (1994). Available at http://iai.asm.org/content/62/6/2536.short

6. Yu, F., Wang, J., Dou, J., Yang, H., He, X., Xu, W., Zhang, Y., Hu, K., Gu, N.: Nanoparticle-based adjuvant for enhanced protective efficacy of DNA vaccine Ag85AESAT-6-IL-21 against Mycobacterium tuberculosis infection. Nanomed Nanotechnol Biol Med 8, 1337-1344 (2012). Available at http://www.sciencedirect.com/science/article/pii/ S1549963412000913

7. Klucar, P., Barnes, P. F., Kong, Y., Howard, S. T., Pang, X., Huang, F. F., Tvinnereim, A. R., Samten, B., Shams, H.: Vaccination strategies to enhance local immunity and protection against Mycobacterium tuberculosis. Vaccine 27, 1816-1824 (2009). Available at http://www.sciencedirect.com/science/article/pii/S0264410X0900156X

8. Welin, A., Björnsdottir, H., Winther, M., Christenson, K., Oprea, T., Karlsson, A., Forsman, H., Dahlgren, C., Bylund, J.: CFP-10 from Mycobacterium tuberculosis selectively activates human neutrophils through a pertussis toxin-sensitive chemotactic receptor. Infect Immun 83, 205-213 (2015). Available at http://iai.asm.org/content/ $83 / 1 / 205$.short

9. Uvarova, E. A., Belavin, P. A., Permyakova, N. V., Zagorskaya, A. A., Nosareva, O. V., Kakimzhanova, A. A., Deineko, E. V.: Oral immunogenicity of plant-made Mycobacterium tuberculosis ESAT6 and CFP10. Biomed Res Int 2013, 316304 (2013). Available at https:// www.hindawi.com/journals/bmri/2013/316304/

10. Seghatoleslam, A., Hemmati, M., Ebadat, S., Movahedi, B., Mostafavi-Pour, Z.: Macrophage immune response suppression by recombinant Mycobacterium tuberculosis antigens, the ESAT-6, CFP-10, and ESAT-6/CFP-10 fusion proteins. Iran J Med Sci 41, 296-304 (2016). Available at https://www.ncbi.nlm.nih.gov/pmc/articles/PMC4912648/

11. Farsiani, H., Mosavat, A., Soleimanpour, S., Sadeghian, H., Eydgahi, M. R. A., Ghazvini, K., Sankian, M., Aryan, E., Jamehdar, S. A., Rezaee, S. A.: Fc-based delivery system enhances immunogenicity of a tuberculosis subunit vaccine candidate consisting of the ESAT-6:CFP-10 complex. Mol BioSyst 12, 2189-2201 (2016). Available at http://pubs. rsc.org/-/content/articlelanding/2016/mb/c6mb00174b/unauth\#!divAbstract

12. Permyakova, N. V., Zagorskaya, A. A., Belavin, P. A., Uvarova, E. A., Nosareva, O. V., Nesterov, A. E., Novikovskaya, A. A., Zav'yalov, E. L., Moshkin, M. P., Deineko, E. V.: Transgenic carrot expressing fusion protein comprising M. tuberculosis antigens induces immune response in mice. Biomed Res Int 2015, 417565 (2015). Available at https://www. hindawi.com/journals/bmri/2015/417565/ 
13. Gupta, U. D., Katoch, V. M.: Animal models of tuberculosis for vaccine development. Indian J Med Res 129, 11-18 (2009). Available at http://www.ijmr.org.in/article.asp?issn=0971$5916 ;$ year $=2009 ;$ volume $=129 ;$ issue $=1 ;$ spage $=11 ;$ epage $=18 ;$ aulast $=$ Gupta;type $=0$

14. Bradford, M. M.: A rapid and sensitive method for the quantitation of microgram quantities of protein utilizing the principle of protein-dye binding. Anal Biochem 72, 248-254 (1976). Available at http://www.sciencedirect.com/science/article/pii/0003269776905273

15. Ufimtseva, E.: Investigation of functional activity of cells in granulomatous inflammatory lesions from mice with latent tuberculous infection in the new ex vivo model. Clin Dev Immunol 2013, 371249 (2013). Available at https://www.hindawi.com/journals/jir/2013/ 371249/

16. Clark, S., Hall, Y., Williams, A.: Animal models of tuberculosis: Guinea pigs. Cold Spring Harb Perspect Med 5, 1-9 (2014). Available at http://perspectivesinmedicine.cshlp.org/ content/5/5/a018572.short

17. Oberg, A. L., Kennedy, R. B., Li, P., Ovsyannikova, I. G., Poland, G. A.: Systems biology approaches to new vaccine development. Curr Opin Immunol 23, 436-443 (2011). Available at https://www.ncbi.nlm.nih.gov/pmc/articles/PMC3129601/

18. Day, J., Schlesinger, L. S., Friedman, A.: Tuberculosis research: Going forward with a powerful ‘Translational Systems Biology' approach. Tuberculosis 90, 7-8 (2010). Available at https://www.ncbi.nlm.nih.gov/pmc/articles/PMC2819545/

19. Jacobs, A. J., Mongkolsapaya, J., Screaton, G. R., McShane, H., Wilkinson, R. J.: Antibodies and tuberculosis. Tuberculosis 101, 102-113 (2016). Available at http:// www.tuberculosisjournal.com/article/S1472-9792(16)30125-1/fulltext

20. Trajkovic, V., Natarajan, K., Sharma, P.: Immunomodulatory action of mycobacterial secretory proteins. Microbes Infect 6, 513-519 (2004). Available at https://www.ncbi.nlm. nih.gov/pubmed/15109967

21. Zvi, A., Ariel, N., Fulkerson, J., Sadoff, J. C., Shafferman, A.: Whole genome identification of Mycobacterium tuberculosis vaccine candidates by comprehensive data mining and bioinformatic analyses. BMC Med Genomics 1, 1-25 (2008). Available at https://bmcmed genomics.biomedcentral.com/articles/10.1186/1755-8794-1-18

22. Wang, X., Wang, Y., Xue, Y., Chen, Y., Tao, Z., Xia, H., Tang, J., Fang, Q.: Construction, identification and immunoreactivity of Mycobacterium tuberculosis DNA vaccine pVAX1/ ESAT-6 plasmid. Nan Fang Yi Ke Da Xue Xue Bao 33, 945-950 (2013). Available at https://www.ncbi.nlm.nih.gov/pubmed/23895830

23. Weldingh, K., Andersen, P.: Immunological evaluation of novel Mycobacterium tuberculosis culture filtrate proteins. FEMS Immunol Med Microbiol 23, 159-164 (1999). Available at https://academic.oup.com/femspd/article/23/2/159/514425/Immunologicalevaluation-of-novel-Mycobacterium

24. Renshaw, P. S., Panagiotidou, P., Whelan, A., Gordon, S. V., Hewinson, R. G., Williamson, R. A., Carr, M. D.: Conclusive evidence that the major T-cell antigens of the Mycobacterium tuberculosis complex ESAT-6 and CFP-10 form a tight, 1:1 complex and characterization of the structural properties of ESAT-6, CFP-10, and the ESAT-6*CFP-10 complex. J Biol Chem 277, 21598-21603 (2002). Available at http://www.jbc.org/content/ 277/24/21598.short

25. Sreejit, G., Ahmed, A., Parveen, N., Jha, V., Valluri, V. L., Ghosh, S., Mukhopadhyay, S.: The ESAT-6 protein of Mycobacterium tuberculosis interacts with beta-2-microglobulin $(\beta 2 \mathrm{M})$ affecting antigen presentation function of macrophage. PLoS Pathog 10, 1-10 
(2014). Available at http://journals.plos.org/plospathogens/article?id=10.1371/journal. ppat. 1004446

26. Champion, J. A., Walker, A., Mitragotri, S.: Role of particle size in phagocytosis of polymeric microspheres. Pharm Res 25, 1815-1821 (2008). Available at https://link. springer.com/article/10.1007/s11095-008-9562-y

27. Lindblad, E. B.: Aluminium compounds for use in vaccines. Immunol Cell Biol 82, 497505 (2004). Available at https://www.ncbi.nlm.nih.gov/pubmed/15479435

28. Karp, C. L., Wilson, C. B., Stuart, L. M.: Tuberculosis vaccines: Barriers and prospects on the quest for a transformative tool. Immunol Rev 264, 363-381 (2015). Available at http:// onlinelibrary.wiley.com/doi/10.1111/imr.12270/full

29. Olsen, A. W., Williams, A., Okkels, L. M., Hatch, G., Andersen, P.: Protective effect of a tuberculosis subunit vaccine based on a fusion of antigen 85B and ESAT-6 in the aerosol guinea pig model. Infect Immun 72, 6148-6150 (2004). Available at http://iai.asm.org/ content/72/10/6148.short

30. Skeiky, Y. W., Alderson, M. R., Ovendale, P. J., Guderian, J., Brandt, L., Dillon, D. C., Campos-Neto, A., Lobet, Y., Dalemans, W., Orme, I. M., Reed, S. G.: Differential immune responses and protective efficacy induced by components of a tuberculosis polyprotein vaccine, Mtb72F, delivered as naked DNA or recombinant protein. J Immunol 172, 76187628 (2004). Available at http://www.jimmunol.org/content/172/12/7618.short

31. Liu, X., Peng, J., Hu, L., Luo, Y., Niu, H., Bai, C., Wang, Q., Li, F., Yu, H., Wang, B., Chen, H., Guo, M., Zhu, B.: A multistage Mycobacterium tuberculosis subunit vaccine LT70 including latency antigen Rv2626c induces long-term protection against tuberculosis. Hum Vaccines Immunother 12, 1670-1677 (2016). Available at http://www.tandfonline. com/doi/abs/10.1080/21645515.2016.1141159 